\title{
Impact of Graft Steatosis on Postoperative Complications after Liver Transplantation
}

\author{
Emad Ali Ahmed, MD ${ }^{1,2}$ Ashraf Mohammad El-Badry, MD ${ }^{2} \quad$ Federico Mocchegiani, MD ${ }^{1}$ \\ Roberto Montalti, MD ${ }^{1}$ Asem Elsani Ali Hassan, MD ${ }^{2}$ Alaa Ahmed Redwan, MD² Marco Vivarelli, MD \\ ${ }^{1}$ Division of Hepatobiliary and Abdominal Transplantation Surgery, \\ Address for correspondence Federico Mocchegiani, MD, Division of \\ Department of Experimental and Clinical Medicine, Polytechnic \\ University of Marche, Ancona, Italy \\ 2 Division of Hepatobiliary and Pancreatic Surgery Unit, Department \\ of General Surgery, University of Sohag, Sohag, Egypt \\ Hepatobiliary and Abdominal Transplantation Surgery, Department of \\ Experimental and Clinical Medicine, Azienda Ospedaliero Universitaria \\ “Ospedali Riuniti," via Conca 71, 60126, Ancona, Italy \\ (e-mail: federicomocchegiani@hotmail.com).
}

Surg J 2018;4:e188-e196.

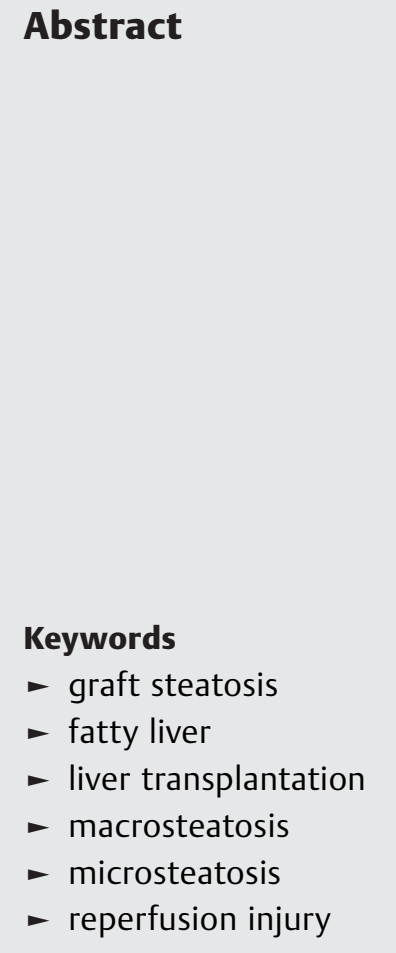

Background Steatotic grafts are more susceptible to ischemia-reperfusion injury than are normal grafts. Therefore, using steatotic grafts for liver transplantation (LT) is associated with high primary dysfunction and decreased survival rates. The aim of this study is to evaluate the impact of graft steatosis on post LT outcomes.

Methods A retrospective cohort analysis of 271 LT recipients from 2005 to 2016 was performed and patients were classified based on two types of steatosis, macrosteatosis (MaS), and microsteatosis (MiS). Each category was subdivided into three groups according to the degree of steatosis: no $(<5 \%)$, mild ( $\geq 5$ to $<30 \%$ ), and moderate ( $\geq 30$ to $\leq 60 \%$ ). The primary hospital stays and 6-month postoperative complications were analyzed by the Clavien-Dindo classification system. Additionally, patient and graft survivals were studied.

Results Significant differences were observed in grade III MaS ( $p$-value $=0.019$ ) and grade V MiS ( $p$-value $=0.020$ ). A high trend of early graft dysfunction was found in the moderate MaS and MiS groups; however, they were not statistically significant ( $p$-value $=0.199$ and 0.282 , respectively). Interestingly, the acute cellular rejection (ACR) rate was found to be inversely proportional to the degree of steatosis in both categories but it did not reach a significant level ( $p$-value $=0.161$ and 0.111 , respectively).

Conclusion Excellent post LT long-term outcomes using grafts with mild and moderate steatosis were determined. Further studies are needed to evaluate the newly proposed relationship between ACR and steatosis.
The number of available grafts for liver transplantation (LT) has failed to keep pace with the needs of the recipient pool of patients. Thus, extending the donor pool remains a critical concern. There are several forms of extended criteria donors who can provide more grafts but the grafts are marginal. Steatosis is considered one of the most widely represented marginal grafts because of the worldwide increasing prevalence of nonalcoholic fatty liver diseases. ${ }^{1}$

received

January 18, 2018 accepted after revision August 30, 2018
DOI https://doi.org/

10.1055/s-0038-1675236. ISSN $2378-5128$
Liver steatosis is subdivided qualitatively into macrosteatosis (MaS) and microsteatosis (MiS). MaS is characterized by a single fat vacuole in hepatocytes, displacing the nucleus to the edge of the cell. In MiS, the cytoplasm of the hepatocytes contains tiny lipid vesicles without nuclear dislocation. Steatosis is further classified quantitatively into mild, moderate, or severe if ( $\geq 5$ to $<30 \%$ ), $(\geq 30$ to $\leq 60 \%$ ), or ( $>60 \%$ ) of hepatocytes, respectively, display fatty infiltrations. ${ }^{2}$

Copyright @ 2018 by Thieme Medical Publishers, Inc., 333 Seventh Avenue, New York, NY 10001, USA. Tel: +1(212) 584-4662.
License terms

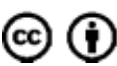


Despite their benign nature, fatty livers may be associated with serious injury including inflammation and hepatocyte necroapoptosis. ${ }^{3}$ In the past, grafts with $\geq 30 \%$ fatty infiltration were not acceptable for transplantation. Furthermore, the use of livers with less fatty infiltration $(<30 \%)$ has been reported to result in bad outcomes after LT. $^{4}$ Recently, some authors reported excellent results after transplantation using severely steatotic livers but with a lower model for end-stage liver disease (MELD) score and shorter ischemia times. ${ }^{5-8}$

Great diversity exists in regard to the impact of the type of steatosis on post LT outcomes. Some authors regard MaS to be more clinically relevant than $\mathrm{MiS}^{9,10}$ while others consider MiS to be an independent risk factor that can affect the early function of the graft. ${ }^{11}$ Cieślak et al observed that a $12 \%$ increase in MiS was equivalent to a $50 \%$ increased risk for postoperative graft dysfunction. ${ }^{12}$

Therefore, our aim was to evaluate the impact of graft steatosis on post LT outcomes.

\section{Methods}

\section{Study Design}

This study is a retrospective cohort study that was a collaboration between Sohag University, Egypt and Polytechnic University of Marche, Italy. Ethical committee approval for the study was obtained with the No. 0113150/02-14. All patients provided informed written consent prior to the transplant procedures and transplant waiting list inclusion. The study protocol was registered at ClinicalTrials.gov as NCT02659553. The study was performed utilizing the "Strengthening the Reporting of Cohort Studies in Surgery (STROCSS)" statement. ${ }^{13}$

\section{Setting and Participants}

The study was conducted at the Division of Hepatobiliary and Abdominal Transplantation Surgery, Department of Experimental and Clinical Medicine, Polytechnic University of Marche, Ancona, Italy. The study included the transplanted cases from August 2005 to April 2016 that matched the eligibility criteria.

\section{Eligibility Criteria}

All adult patients who underwent primary LT with a preoperative histopathological report of the donor graft determining the type and degree of fatty infiltration were included in this study. Retransplanted patients and patients with no preoperative determination of the type and/ or degree of graft steatosis were excluded from the study.

\section{Data Collection}

The patients' records of 271 recipients that matched our eligibility criteria were analyzed for any postoperative complications during the primary hospital stay (from the date of LT to the date of discharge). Overall complications during the first 6 postoperative months and long-term patient and graft survivals were also studied.

The severity of the liver disease of the recipients was assessed by MELD score. ABO blood group compatible grafts from deceased heart-beating donors with accepted liver func- tion tests were used for all participants. Organ procurement was performed according to the standard techniques with the back-table preparation of the graft. A graft biopsy was obtained using a true-cut needle at the time of procurement. Grafts were preserved using Celsior $(n=262)$, University of Wisconsin $(n=8)$, or Histidine-Tryptophan-Ketoglutarate $(n=1)$ solutions and placed on ice.

Recipient total hepatectomy followed by LT using the conventional $(n=19)$, piggyback $(n=247)$, or piggyback variant $(n=5)$ technique was performed. Then, end-to-end porto-portal vein (porto-PV) anastomosis $(n=266)$, the cavoportal hemitransposition technique $(n=3)$, or bypass porto-mesenteric anastomosis $(n=2)$ was performed. The hepatic arterial circulation was maintained through end-toend hepatic artery anastomosis $(n=247)$, celiac-hepatic $(n=6)$, celiac-celiac $(n=2)$, celiac-aortic $(n=6)$, or hepatic-aortic anastomosis $(n=10)$. Biliary reconstruction was performed by end-to-end choledochocholedochostomy ( $n=257$ ) or hepaticojejunostomy $(n=14)$.

In our institution, $500 \mathrm{mg}$ of steroids plus $20 \mathrm{mg}$ of basiliximab were administered at the time of perfusion. Then, postoperative immunosuppressive schemes were tailored for each patient but they were predominantly based on steroids, tacrolimus, and/or basiliximab.

During the hospital stay, postoperative graft follow-up was achieved by daily measurements of transaminases, albumin, bilirubin, and the international normalized ratio (INR). A duplex examination was performed routinely every day for the first postoperative week, then every other day until hospital discharge, then monthly for the first year. A postoperative graft biopsy was not routinely done in our center except when there was clinical or biochemical evidence of graft dysfunction.

\section{Study Variables and Measurements}

Steatosis was considered the factor of interest in this study. Qualitatively patients were divided into two categories: MaS or MiS. Each category was subdivided quantitatively into three groups: control group with no steatosis ( $<5 \%)$, compared with mild ( $\geq 5$ to $<30 \%$ ), and moderate ( $\geq 30$ to $\leq 60 \%$ ) steatosis.

These groups were analyzed for any major postoperative negative outcomes during the hospital stay based on the Clavien-Dindo classification with definitions specified for LT. ${ }^{14,15}$ Other outcomes of interest included primary nonfunction (PNF), early graft dysfunction (EGD), acute cellular rejection (ACR), biliary complications, and patient and graft survivals.

PNF was defined as graft failure soon after reperfusion without an obvious cause leading to either retransplantation or death in the first postoperative week. It was diagnosed by (1) an increased aspartate transaminase (AST) level $\geq 3,000 \mathrm{U} / \mathrm{L}$ and (2) INR $\geq 2.5$ and/or acidosis (arterial $\mathrm{pH} \leq 7.30$ or venous $\mathrm{pH} \leq 7.25$ and/or lactate $\geq 4 \mathrm{mmol} / \mathrm{L})^{16}$

EGD was defined as impaired initial graft function with a high peak serum transaminase and persistently high bilirubin levels. It was diagnosed by measurement of one or more of the following values: bilirubin $\geq 10 \mathrm{mg} / \mathrm{dL}$ on day 7 , INR $\geq 1.6$ on day 7 , and AST $>2,000 \mathrm{IU} / \mathrm{L}$ within the first 7 days. ${ }^{17}$ 
ACR was broadly defined as graft inflammation elicited by genetic disparity between the donor and recipient. Graft biopsy, obtained using a true-cut needle, remains the gold standard for ACR diagnosis. ${ }^{18}$

Bile leakage is defined as a fluid with an increased bilirubin concentration (three times greater than the serum bilirubin measured at the same time) in the abdominal drain or in the intra-abdominal fluid on or after postoperative day (POD) 3 or as the need for radiologic intervention or relaparotomy. ${ }^{19}$ Biliary stricture is an abnormal narrowing of the bile duct associated with rising cholestasis indexes that required invasive management, such as endoscopic retrograde cholangiopancreatography, percutaneous transhepatic drainage, or resurgery. ${ }^{20}$

Acute postoperative vascular complications including portal vein thrombosis (PVT), hepatic artery thrombosis (HAT), and haemoperitoneum were studied. Postoperative ascites, renal insufficiency, hepatitis $C$ virus (HCV) recurrence, and intensive care unit (ICU) and hospital stays were also evaluated.

Patient survival was calculated from the date of transplantation to the date of patient death. Graft survival was calculated from the date of transplantation to the date of irreversible graft failure, retransplantation, or the date of death.

\section{Bias Assessment}

All records were independently reviewed by the endpoint assessment committee which included certified surgeons and gastroenterologists. All members of the end point assessment committee were blinded to the study participants' baseline risk factor information.

\section{Statistical Analysis}

Continuous variables were presented as the means and standard deviation while categorical variables were expressed as percentages. Quantitative variables were compared using a one-way ANOVA (analysis of variance) test. For qualitative variables, Pearson's Chi-square tests were used after assumptions had been verified. A 95\% confidence interval $(\mathrm{CI})$ was reported for both measures. Graft and patient survival rates were described and compared using a Kaplan-Meier test. A $p$-value $<0.05$ was considered statistically significant. All statistical tests were performed using IBM SPSS Statistics for Windows, Armonk, NY: IBM Corp, Version 20.

\section{Results}

\section{Participants and Descriptive Data}

From August 2005 to April 2016, 271 cases matched our inclusion and exclusion criteria and were included in this study. The primary indications for LT in the selected patients are shown in -Table 1 and included end-stage liver disease due to hepatitis $(n=178)$, alcoholism $(n=45)$, or other ( $n=46)$, and/or HCC (hepatocellular carcinoma; $n=103$ ), cholangiocarcinoma $(n=1)$, or complicated adenoma $(n=1)$. To the best of our knowledge, all cases of HCC were associated with a different liver pathology. Regarding the type and degree of graft steatosis, 125 patients received grafts with MaS of which 109 were mild and 16 were moderate. Additionally, 96 patients received grafts with MiS of which 77 were mild and 19 were moderate. The clinicopathological features of the donors and recipients are listed in -Table 1.

In the MaS category, the only significant difference was in the donor body mass index (BMI) which was lower in the control group than in the mild and moderate groups $(25.38 \pm 3.01$ vs. $27.16 \pm 4.25$ vs. $27.87 \pm 4.21, p=0.000$, respectively). Moreover, the D-MELD (donor-MELD) score was much lower in the moderate group than in the control and mild groups but the scores were not significantly different ( $740.94 \pm 396.98$ vs. $1100.07 \pm 643.3$ vs. $1127.6 \pm 600.17$ $p=0.062$, respectively).

In the MiS category, the only significant difference was the donor age which was markedly lower in the moderate group than in the control and mild groups (55.00 \pm 19.62 vs. $61.36 \pm 17.00$ vs. $65.35 \pm 13.65, p=0.031$, respectively).

The operative parameters and ischemia times are listed in - Table 2. No differences were noted among any groups within MaS and MiS in regard to the cold ischemia time (CIT), total ischemia time (TIT), or surgical time.

\section{Outcome Data and Main Results}

\section{Impact of Graft MaS on Post LT Outcomes}

According to the Clavien-Dindo grading of in-hospital complications (-Table 3), a significant difference in the grade III complication rate $(p=0.019)$ was detected among the groups with a higher rate in the moderate group (31\%) than in the control (nonsteatotic; 23\%) and mild (11\%) groups. This difference was also observed between the moderate $(p=0.027)$ and control $(p=0.012)$ groups when compared with the mild group separately. No significant difference was noted when comparing the moderate and control groups $(p=0.479)$. An increase in the grade IV complication rate was also observed in the moderate group (12.5\%) compared with the control and mild groups (3.4 and $1.8 \%$, respectively) but the difference did not reach statistical significance $(p=0.084)$. No significant difference was detected among the groups in regard to the grade V complication rate $(p=0.215)$.

Regarding the overall complications encountered after LT (-Table 3), one patient in the moderate group (6.2\%), five in the mild group (4.6\%) and four in the control group (2.7\%) had experienced PNF, with no statistical increase in PNF $(p=0.634)$. In addition, there was a higher rate of EGD and acute HAT when comparing the moderate group (56.2 and $12.5 \%$, respectively) with the mild (35.8 and $3.7 \%$, respectively) and control (33.6 and 2.7\%, respectively) groups. Although there was a large difference in the rates of EGD and HAT, no statistical significance was observed ( $p=0.199$ and 0.145 , respectively). Conversely, the ACR rate was higher in the control and mild groups compared with the moderate group (39.7, 32 , and $18.8 \%$, respectively) but it did not reach a significant level $(p=0.161)$. 
Table 1 Demographic and clinicopathological criteria of all participants

\begin{tabular}{|c|c|c|c|c|c|c|c|c|}
\hline \multirow{2}{*}{$\begin{array}{l}\text { Type of steatosis } \\
\text { Degree of steatosis }\end{array}$} & \multicolumn{4}{|c|}{ Macrosteatosis $(n=271)$} & \multicolumn{4}{|c|}{ Microsteatosis $(n=271)$} \\
\hline & $\begin{array}{l}\text { No } \\
n=146\end{array}$ & $\begin{array}{l}\text { Mild } \\
n=109\end{array}$ & $\begin{array}{l}\text { Moderate } \\
n=16\end{array}$ & $p$-Value & $\begin{array}{l}\text { No } \\
n=175\end{array}$ & $\begin{array}{l}\text { Mild } \\
n=77\end{array}$ & $\begin{array}{l}\text { Moderate } \\
n=19\end{array}$ & $p$-Value \\
\hline \multicolumn{9}{|c|}{ Donor criteria $(n=271)$} \\
\hline Age $(y)$ & $60.9 \pm 17.74$ & $64.3 \pm 14.26$ & $57.2 \pm 17.37$ & 0.126 & $61.36 \pm 17.00$ & $65.35 \pm 13.65$ & $55.00 \pm 19.62$ & 0.031 \\
\hline $\operatorname{Sex}(m / f)$ & $75 / 71$ & $62 / 47$ & $10 / 6$ & 0.540 & $99 / 76$ & $38 / 39$ & $10 / 9$ & 0.564 \\
\hline D-MELD score & $1,100 \pm 643$ & $1,127.6 \pm 600$ & $740.9 \pm 396.9$ & 0.062 & $1,073.7 \pm 625.7$ & $1,182.8 \pm 615$ & $863 \pm 518.7$ & 0.110 \\
\hline DRI & $1.86 \pm 0.59$ & $1.95 \pm 0.75$ & $1.68 \pm 0.38$ & 0.261 & $1.89 \pm 0.64$ & $1.92 \pm 0.70$ & $1.60 \pm 0.40$ & 0.162 \\
\hline BMI $\left(\mathrm{kg} / \mathrm{m}^{2}\right)$ & $25.38 \pm 3.01$ & $27.16 \pm 4.25$ & $27.87 \pm 4.21$ & 0.000 & $26.24 \pm 3.96$ & $26.28 \pm 3.36$ & $26.15 \pm 3.28$ & 0.991 \\
\hline $\operatorname{ALT}(\mathrm{U} / \mathrm{L})$ & $47.28 \pm 64.06$ & $39.52 \pm 42.75$ & $50.4 \pm 50.07$ & 0.513 & $44.61 \pm 56.75$ & $40.03 \pm 46.39$ & $59.89 \pm 77.56$ & 0.401 \\
\hline AST (U/L) & $49.8 \pm 64.75$ & $47.36 \pm 52.9$ & $68.0 \pm 93.38$ & 0.490 & $48.92 \pm 62.24$ & $47.45 \pm 55.8$ & $68.56 \pm 84.54$ & 0.416 \\
\hline PT-INR & $3.73 \pm 16.9$ & $4.05 \pm 17.05$ & $1.21 \pm 0.26$ & 0.845 & $4.89 \pm 20.12$ & $1.44 \pm 1.26$ & $1.29 \pm 0.15$ & 0.327 \\
\hline $\mathrm{Na}$ & $150.05 \pm 9.71$ & $150.2 \pm 9.08$ & $148.9 \pm 10.9$ & 0.880 & $149.73 \pm 9.48$ & $150.54 \pm 9.65$ & $151.12 \pm 9.45$ & 0.743 \\
\hline ICU stay $(d)$ & $4.67 \pm 4.19$ & $4.67 \pm 4.35$ & $4.4 \pm 3.38$ & 0.972 & $4.69 \pm 4.22$ & $4.73 \pm 4.35$ & $4.05 \pm 3.55$ & 0.810 \\
\hline \multicolumn{9}{|l|}{ Cause of death } \\
\hline $\begin{array}{l}\text { Cerebral } \\
\text { hemorrhage }\end{array}$ & $91(62.3)$ & $65(59.6)$ & $7(43.8)$ & 0.868 & $106(60.6)$ & $48(62.3)$ & $9(47.4)$ & 0.908 \\
\hline Cranial trauma & 29 (19.9) & $23(21.1)$ & $7(43.8)$ & 0.868 & $36(20.6)$ & $15(19.5)$ & $8(42)$ & 0.908 \\
\hline Brain anoxia & $13(8.9)$ & $10(9.2)$ & $1(6.2)$ & 0.868 & $16(9)$ & $6(7.8)$ & $2(10.5)$ & 0.908 \\
\hline Ischemic stroke & $9(6.2)$ & $9(8.3)$ & $1(6.2)$ & 0.868 & $11(6.3)$ & $8(10.4)$ & $0(0)$ & 0.908 \\
\hline Others & $4(2.7)$ & $2(1.8)$ & $0(0)$ & 0.868 & $6(3.4)$ & $0(0)$ & $0(0)$ & 0.908 \\
\hline \multicolumn{9}{|c|}{ Recipient criteria $(n=271)$} \\
\hline Age (y) & $53.84 \pm 8.35$ & $52.53 \pm 9.39$ & $56.75 \pm 6.68$ & 0.152 & $53.62 \pm 8.62$ & $53.35 \pm 8.99$ & $52.74 \pm 9.12$ & 0.905 \\
\hline $\operatorname{Sex}(m / f)$ & $111 / 35$ & $83 / 26$ & $11 / 5$ & 0.803 & $131 / 44$ & $58 / 19$ & $16 / 3$ & 0.664 \\
\hline MELD score & $17.84 \pm 8.25$ & $16.09 \pm 7.49$ & $19.50 \pm 7.22$ & 0.110 & $17.34 \pm 7.99$ & $17.26 \pm 7.56$ & $16.16 \pm 9.12$ & 0.828 \\
\hline BMI $\left(\mathrm{kg} / \mathrm{m}^{2}\right)$ & $24.71 \pm 3.99$ & $25.1 \pm 4.23$ & $25.37 \pm 3.54$ & 0.678 & $25.30 \pm 4.25$ & $24.03 \pm 3.47$ & $24.84 \pm 3.99$ & 0.072 \\
\hline \multicolumn{9}{|l|}{ Indications of LT } \\
\hline $\mathrm{HCV}$ & $69(47.3)$ & $54(49.5)$ & $7(43.4)$ & 0.830 & $88(50.3)$ & $37(48)$ & $5(26.3)$ & 0.445 \\
\hline Plus, HCC & $55(37.7)$ & $40(36.7)$ & $8(50)$ & 0.830 & $71(40.6)$ & $27(35)$ & $5(26.3)$ & 0.445 \\
\hline Alcoholic & $25(17)$ & $15(13.8)$ & $5(31.3)$ & 0.830 & $28(16)$ & $12(15.6)$ & $5(26.3)$ & 0.445 \\
\hline Cryptogenic & $13(9)$ & $9(8.3)$ & $1(6.3)$ & 0.830 & $16(9)$ & $6(7.8)$ & $1(5.3)$ & 0.445 \\
\hline HBV & $12(8)$ & $10(9.2)$ & $2(12.5)$ & 0.830 & $11(6.3)$ & $10(13)$ & $3(15.8)$ & 0.445 \\
\hline HBV-HDV & $8(5.5)$ & $9(8.3)$ & $0(0)$ & 0.830 & $12(6.9)$ & $4(5.2)$ & $1(5.3)$ & 0.445 \\
\hline Cholestasis & $10(7)$ & $3(2.8)$ & $1(6.3)$ & 0.830 & $9(5)$ & $3(3.9)$ & $2(10.5)$ & 0.445 \\
\hline Others & $9(6)$ & $9(8)$ & $0(0)$ & 0.830 & $11(6.3)$ & $5(6.5)$ & $2(10.5)$ & 0.445 \\
\hline $\operatorname{ALT}(\mathrm{U} / \mathrm{L})$ & $69.6 \pm 94.6$ & $216.9 \pm 1047$ & $43.88 \pm 31.44$ & 0.202 & $82.41 \pm 175.4$ & $243 \pm 1,228$ & $73.37 \pm 150$ & 0.212 \\
\hline AST (U/L) & $100.9 \pm 110$ & $297.5 \pm 1410$ & $63.62 \pm 48.3$ & 0.205 & $107.8 \pm 159.6$ & $357.7 \pm 1663$ & $86.47 \pm 97$ & 0.122 \\
\hline PT-INR & $5.73 \pm 24.16$ & $5.0 \pm 24.19$ & $1.81 \pm 0.75$ & 0.813 & $4.81 \pm 20.42$ & $6.83 \pm 31.42$ & $2.21 \pm 2.7$ & 0.695 \\
\hline
\end{tabular}

Abbreviations: ALT, alanine transaminase; AST, aspartate transaminase; BMI, body mass index; D-MELD, donor-model end-stage liver disease; DRI, donor risk index; HBV, hepatitis B virus; HCC, hepatocellular carcinoma; HCV, hepatitis C virus, HDV, hepatitis D virus; ICU, intensive care unit; LT, liver transplantation; PT/INR, prothrombin time/international normalized ratio.

Within the first postoperative 6 months, no cases of postoperative bile leakage or HCV recurrence were documented in the moderate group compared with the control (11.6 and 9.6\%, respectively) and mild (12.8 and 8.3\%, respectively) groups, and there was no significant difference among the groups ( $p=0.319$ and 0.423 , respectively). Nearly equal results were obtained among all MaS groups in regard to the rates of postoperative ascites, biliary stricture, haemoperitoneum, PVT, and renal failure $(p=0.441,0.946,0.996$, 0.858 , and 0.460 , respectively).
As described in -Table 4, there were no significant differences among the 1-, 3-, and 5-year patient and graft survivals among the MaS groups $(p=0.184$ and 0.262 , respectively). Survival plots of patient and graft survivals are shown in $\boldsymbol{- F i g s .} \mathbf{1}$ and $\mathbf{2}$, respectively.

\section{Impact of Graft MiS on Post LT Outcomes}

As summarized in -Table 3, a significant difference was noticed in the grade $\mathrm{V}$ complication rate among the MiS groups $(p=0.020)$, with a higher rate in the mild group $(19.5 \%)$ 
e192 Steatosis Impact on Liver Transplantation Outcomes Ahmed et al.

Table 2 Operative parameters of all patients

\begin{tabular}{|c|c|c|c|c|c|c|c|c|}
\hline \multirow{2}{*}{$\begin{array}{l}\begin{array}{l}\text { Type of } \\
\text { steatosis }\end{array} \\
\begin{array}{l}\text { Degree of } \\
\text { steatosis }\end{array}\end{array}$} & \multicolumn{4}{|c|}{ Macrosteatosis $(n=271)$} & \multicolumn{4}{|c|}{ Microsteatosis $(n=271)$} \\
\hline & $\begin{array}{l}\text { No } \\
n=146\end{array}$ & $\begin{array}{l}\text { Mild } \\
n=109\end{array}$ & $\begin{array}{l}\text { Moderate } \\
n=16\end{array}$ & $p$-Value & $\begin{array}{l}\text { No } \\
n=175\end{array}$ & $\begin{array}{l}\text { Mild } \\
n=77\end{array}$ & $\begin{array}{l}\text { Moderate } \\
n=19\end{array}$ & $p$-Value \\
\hline CIT (min.) & $\begin{array}{l}433.13 \pm \\
113.46\end{array}$ & $414.62 \pm 121.98$ & $440.56 \pm 150.08$ & 0.419 & $\begin{array}{l}423.16 \pm \\
111.98\end{array}$ & $428.10 \pm 130.68$ & $445.84 \pm 138.39$ & 0.724 \\
\hline WIT (min.) & $\begin{array}{l}32.51 \pm \\
10.63\end{array}$ & $43.12 \pm 66.63$ & $44.63 \pm 20.38$ & 0.123 & $\begin{array}{l}37.09 \pm \\
45.89\end{array}$ & $39.13 \pm 42.68$ & $34.21 \pm 11.09$ & 0.891 \\
\hline TIT (min.) & $\begin{array}{l}465.64 \pm \\
114.56\end{array}$ & $457.74 \pm 113.23$ & $485.19 \pm 156.5$ & 0.650 & $\begin{array}{l}460.25 \\
110.26\end{array}$ & $467.23 \pm 124.52$ & $480.05 \pm 142.46$ & 0.743 \\
\hline $\begin{array}{l}\text { Operative } \\
\text { time (min.) }\end{array}$ & $\begin{array}{l}421.68 \pm \\
79.43\end{array}$ & $416.87 \pm 90.88$ & $461.56 \pm 108.8$ & 0.154 & $\begin{array}{l}426.03 \pm \\
90.82\end{array}$ & $411.16 \pm 77.87$ & $430.79 \pm 75.62$ & 0.410 \\
\hline
\end{tabular}

Abbreviations: CIT, cold ischemia time; TIT, total ischemia time; WIT, warm ischemia time.

compared with the control (nonsteatotic) and moderate groups ( 8.0 and $5.3 \%$, respectively). This difference emerged between the mild and control groups only ( $p=0.009$ ) with no differences found between the moderate and mild groups $(p=0.136)$ or the moderate and control groups $(p=0.671)$. No statistical differences were observed in the grade III and IV complications rate ( $p=0.640$ and 0.186 , respectively).

Regarding the overall complications encountered after LT ( - Table 3 ), five cases of PNF were observed in both the mild (6.5\%) and the control (2.9\%) groups, with no PNF in the moderate group. These results were not significantly different $(p=0.250)$. Additionally, there was a higher rate of EGD in the moderate group of patients (52.6\%) than in the mild
(35.1\%) and control (34.3\%) groups, respectively but these results were not significant $(p=0.282)$. Like MaS, the ACR rate was higher in the control and mild groups than in the moderate group (39, 32.5 , and $15.8 \%$, respectively) but the differences were not significant $(p=0.111$ ).

Within the first 6 postoperative months, a higher frequency of $\mathrm{HCV}$ recurrence was observed in the control (9.7\%) and mild (9.1\%) MiS groups; no cases were observed in the moderate group $(p=0.366)$. Moreover, nearly equal results were obtained among all MiS groups in regard to the rates of postoperative HAT, PVT, ascites, biliary leakage, biliary strictures, haemoperitoneum, and renal failure $(p=0.676,0.435,0.524$, $0.137,0.999,0.531$, and 0.734 , respectively).

Table 3 Postoperative outcomes after liver transplantation

\begin{tabular}{|c|c|c|c|c|c|c|c|c|}
\hline \multirow{2}{*}{$\begin{array}{l}\text { Type of steatosis } \\
\text { Degree of steatosis }\end{array}$} & \multicolumn{4}{|c|}{ Macrosteatosis $(n=271)$} & \multicolumn{4}{|c|}{ Microsteatosis $(n=271)$} \\
\hline & $\begin{array}{l}\text { No } \\
n=146\end{array}$ & $\begin{array}{l}\text { Mild } \\
n=109\end{array}$ & $\begin{array}{l}\text { Moderate } \\
n=16\end{array}$ & $p$-Value & $\begin{array}{l}\text { No } \\
n=175\end{array}$ & $\begin{array}{l}\text { Mild } \\
n=77\end{array}$ & $\begin{array}{l}\text { Moderate } \\
n=19\end{array}$ & $p$-Value \\
\hline \multicolumn{9}{|l|}{ Overall complication } \\
\hline PNF & $4(2.7)$ & $5(4.6)$ & $1(6.2)$ & 0.634 & $5(2.9)$ & $5(6.5)$ & $0(0.0)$ & 0.250 \\
\hline EGD & $49(33.6)$ & $39(35.8)$ & $9(56.2)$ & 0.199 & $60(34.3)$ & $27(35.1)$ & $10(52.6)$ & 0.282 \\
\hline PVT & $2(1.4)$ & $1(0.9)$ & $0(0.0)$ & 0.858 & $3(1.7)$ & $0(0.0)$ & $0(0.0)$ & 0.435 \\
\hline Acute HAT & $4(2.7)$ & $4(3.7)$ & $2(12.5)$ & 0.145 & $7(4.0)$ & $3(3.9)$ & $0(0.0)$ & 0.676 \\
\hline Ascites & $27(18.5)$ & $14(12.8)$ & $2(12.5)$ & 0.441 & $26(14.9)$ & $15(19.5)$ & $2(10.5)$ & 0.524 \\
\hline Bile leakage & $17(11.6)$ & $14(12.8)$ & $0(0.0)$ & 0.319 & $13(7.4)$ & $12(15.6)$ & $2(10.5)$ & 0.137 \\
\hline Biliary stricture & $24(16.4)$ & $17(15.6)$ & $3(18.8)$ & 0.946 & $27(15.4)$ & $12(15.6)$ & $3(15.8)$ & 0.999 \\
\hline Haemoperitoneum & $9(6.2)$ & $7(6.4)$ & $1(6.2)$ & 0.996 & $9(5.1)$ & $6(7.8)$ & $2(10.5)$ & 0.531 \\
\hline Renal failure & $17(11.6)$ & $8(7.3)$ & $1(6.2)$ & 0.460 & $15(8.6)$ & $9(11.7)$ & $2(10.5)$ & 0.734 \\
\hline ACR & $58(39.7)$ & $35(32)$ & $3(18.8)$ & 0.161 & $68(39)$ & $25(32.5)$ & $3(15.8)$ & 0.111 \\
\hline HCV recurrence & $14(9.6)$ & $9(8.3)$ & $0(0.0)$ & 0.423 & $17(9.7)$ & $7(9.1)$ & $0(0.0)$ & 0.366 \\
\hline Retransplantation & $6(4)$ & $6(5.5)$ & $0(0.0)$ & 0.584 & $8(4.6)$ & $3(4)$ & $1(5.3)$ & 0.955 \\
\hline \multicolumn{9}{|c|}{ Hospital stay complications as graded by Clavien-Dindo } \\
\hline Grade III & $34(23.3)$ & $12(11)$ & $5(31)$ & 0.019 & $34(19.4)$ & $13(17)$ & $5(26.3)$ & 0.640 \\
\hline Grade IV & $5(3.4)$ & $2(1.8)$ & $2(12.5)$ & 0.084 & $6(3.4)$ & $0(0)$ & $0(0)$ & 0.186 \\
\hline Grade V & $12(8.2)$ & $16(14.7)$ & $1(6.2)$ & 0.215 & $14(8.0)$ & $15(19.5)$ & $1(5.3)$ & 0.020 \\
\hline ICU stay (d) & $7.81 \pm 32.46$ & $5.25 \pm 7.45$ & $9.2 \pm 9.6$ & 0.696 & $7.71 \pm 29.96$ & $5.62 \pm 6.47$ & $4.24 \pm 3.47$ & 0.765 \\
\hline Hospital stay (d) & $21.43 \pm 12.64$ & $20.03 \pm 13.44$ & $21.6 \pm 10.76$ & 0.719 & $21.33 \pm 13.56$ & $20.15 \pm 11.75$ & $19.94 \pm 9.11$ & 0.788 \\
\hline
\end{tabular}

Abbreviations: ACR, acute cellular rejection; EGD, early graft dysfunction; HAT, hepatic artery thrombosis; HCV, hepatitis C virus; ICU, intensive care unit; PNF, primary nonfunction; PVT, portal vein thrombosis. 
Table 4 Patients and grafts survivals

\begin{tabular}{|c|c|c|c|c|c|c|}
\hline \multirow{2}{*}{$\begin{array}{l}\text { Type of steatosis } \\
\text { Degree of steatosis }\end{array}$} & \multicolumn{3}{|c|}{ Macrosteatosis $(n=271)$} & \multicolumn{3}{|c|}{ Microsteatosis $(n=271)$} \\
\hline & $\begin{array}{l}\text { No } \\
n=146\end{array}$ & $\begin{array}{l}\text { Mild } \\
n=109\end{array}$ & $\begin{array}{l}\text { Moderate } \\
n=16\end{array}$ & $\begin{array}{l}\text { No } \\
n=175\end{array}$ & $\begin{array}{l}\text { Mild } \\
n=77\end{array}$ & $\begin{array}{l}\text { Moderate } \\
n=19\end{array}$ \\
\hline Patient survival & \multicolumn{3}{|c|}{$p=0.184$} & \multicolumn{3}{|c|}{$p=0.347$} \\
\hline 1-year & 83 & 77 & 94 & 84 & 73 & 89 \\
\hline 3-year & 78 & 67 & 88 & 77 & 68 & 83 \\
\hline 5-year & 75 & 57 & 81 & 72 & 61 & 76 \\
\hline Graft survival & \multicolumn{3}{|c|}{$p=0.262$} & \multicolumn{3}{|c|}{$p=0.459$} \\
\hline 1-year & 79 & 77 & 94 & 81 & 71 & 89 \\
\hline 3-year & 75 & 66 & 88 & 75 & 67 & 83 \\
\hline 5-year & 72 & 56 & 81 & 69 & 60 & 76 \\
\hline
\end{tabular}

As described in -Table 4, there were no significant differences between the 1-, 3-, and 5-year patient and graft survivals among the MiS groups $(p=0.347$ and 0.459 , respectively). Survival plots of patient and graft survivals are shown in -Figs. 3 and 4, respectively.

\section{Discussion}

Several donor and recipient risk factors can contribute to post LT outcomes. Therefore in this study, the D-MELD and DRI (donor risk index) scores were carefully reviewed and found to be of lower values in cases of increased steatosis. Conversely, the recipient age and MELD score were not greatly considered in relation to the degree of steatosis.
Furthermore, CIT and TIT were not considered in regard to the degree or type of steatosis, trending toward a longer duration in the moderate groups of both categories. The maximum CIT in all study groups did not exceed 10 hours.

From the results, it seems that the steatosis type or degree were not the main risk factors for post LT complication rate. Additionally, Wong et al demonstrated no significant difference in grade III, IV, and V complications between severely steatotic grafts versus a control group. ${ }^{7}$ Moreover, Westerkamp et al reported a significant increase only in the grade IV complication rate in a moderate MaS group compared with a control group (53 vs. 13\%, respectively). The majority of these complications were related to single organ failure including respiratory or renal insufficiency. ${ }^{21}$

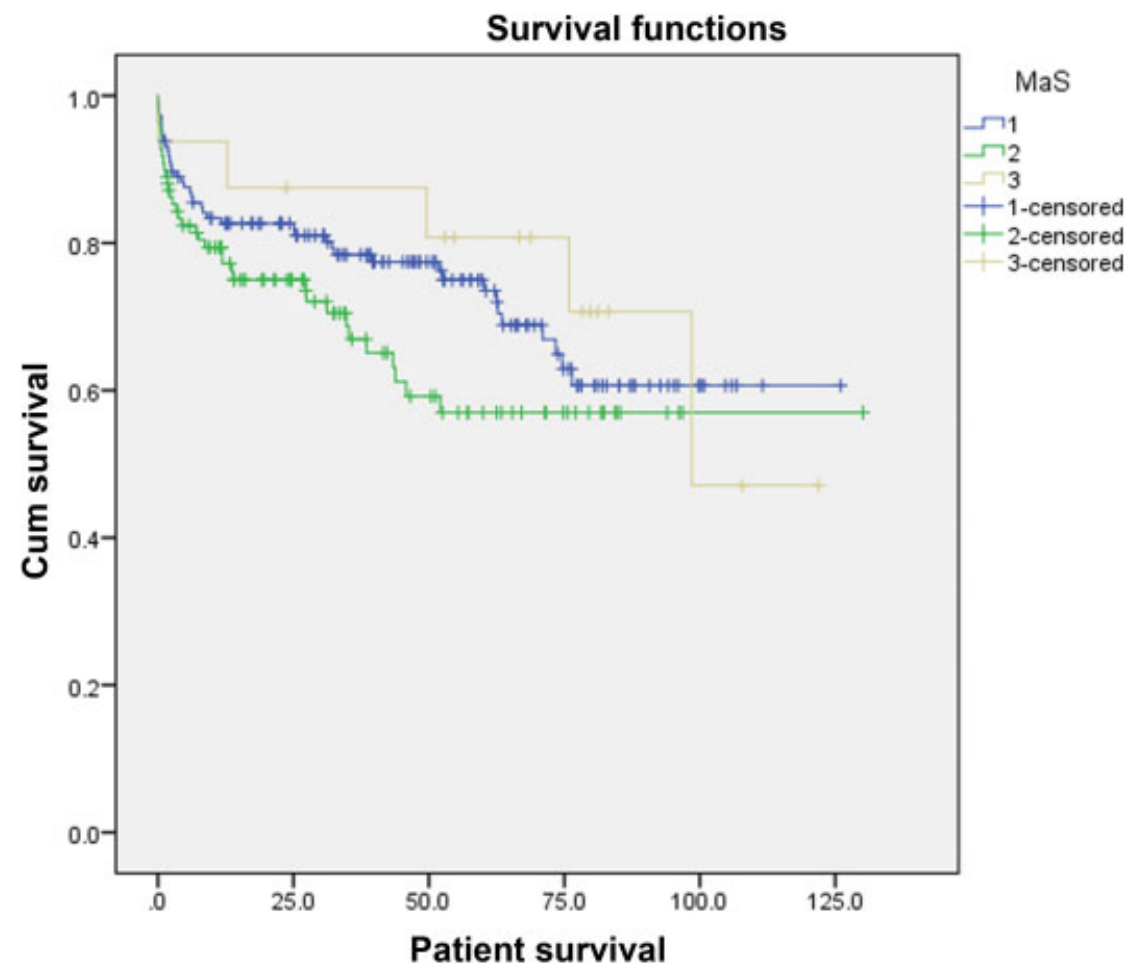

1;No steatosis, 2; Mild steatosis, 3; Moderate steatosis

Fig. 1 Survival plot of the patients in the macrosteatosis groups. 
e194 Steatosis Impact on Liver Transplantation Outcomes Ahmed et al.

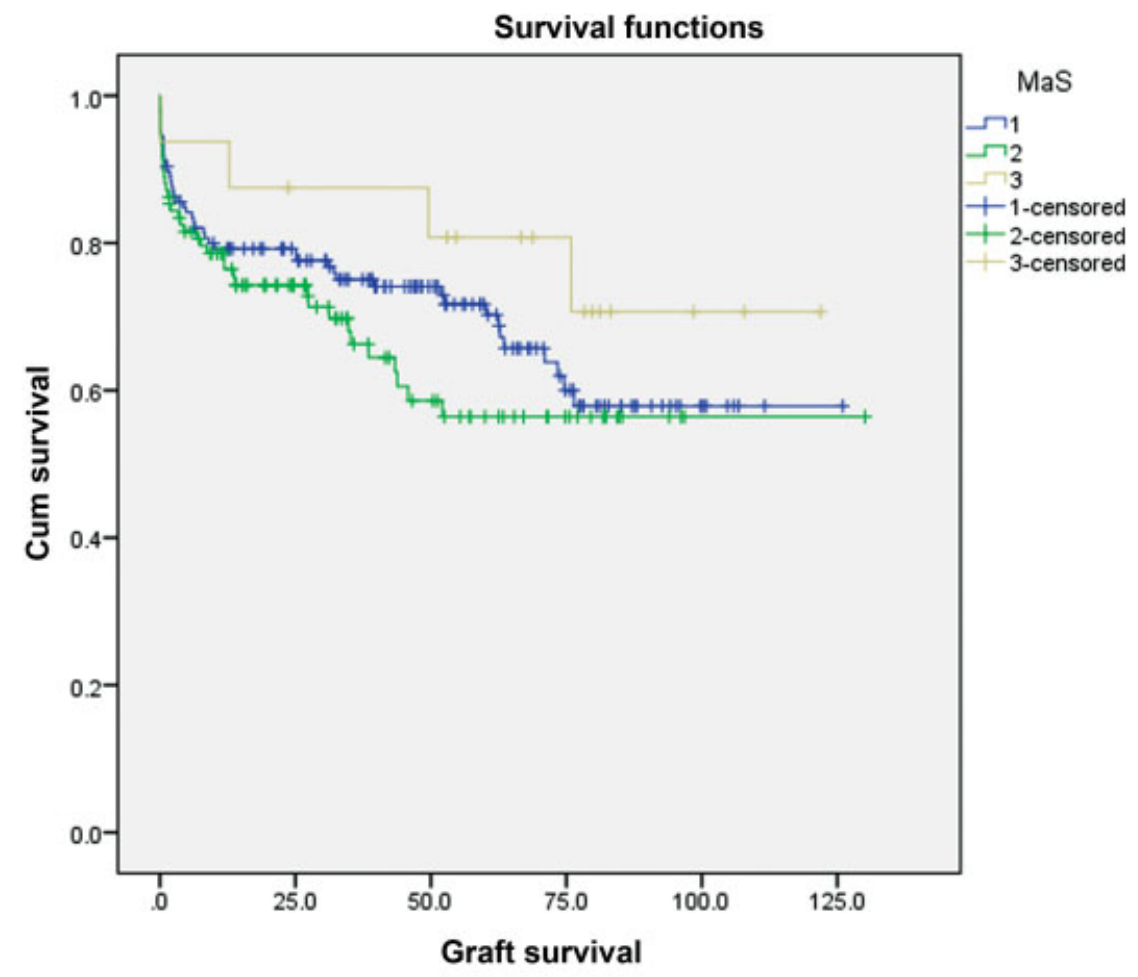

1; No steatosis, 2; Mild steatosis, 3; Moderate steatosis

Fig. 2 Survival plot of the grafts in the macrosteatosis groups.

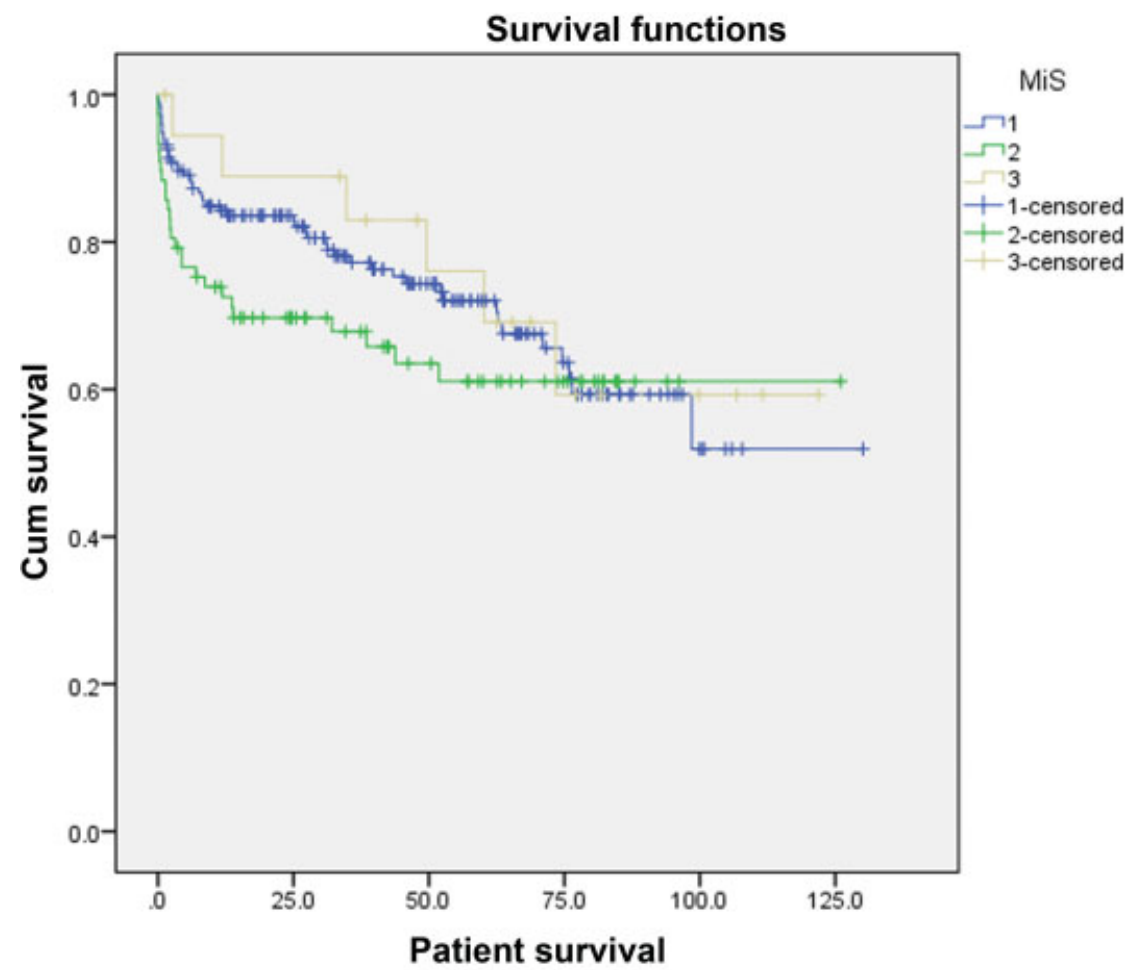

1; No steatosis, 2; Mild steatosis, 3; Moderate steatosis

Fig. 3 Survival plot of the patients in the microsteatosis groups.

Although the rates of EGD paralleled the degree of steatosis in MaS and MiS and were the highest in the moderate groups (56.2 and 52.6\%, respectively), no statistical significance was observed. Similarly, no significant differences were noted in the MaS and MiS groups in regard to postoperative PNF, retransplantation, PVT, HAT, haemoperitoneum, renal insufficiency, or ascites. Likewise, previous reports described early poor liver function and bilirubin levels in the moderate graft 


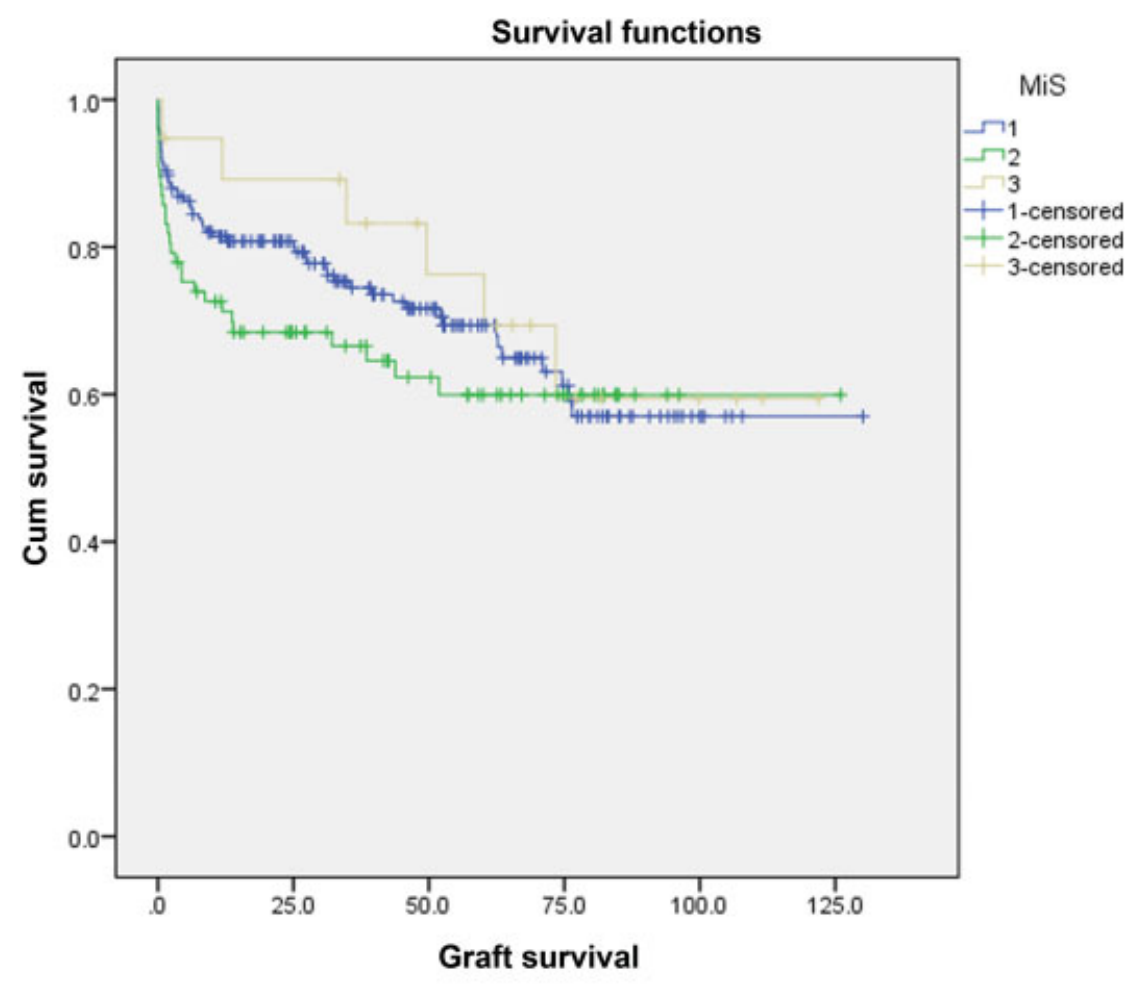

1;No steatosis, 2;Mild steatosis, 3; Moderate steatosis

Fig. 4 Survival plot of the grafts in the microsteatosis groups.

steatosis group within the first 2 days after LT. These undesirable outcomes became comparable with the control groups on POD 7 without any significant differences in the rates of EGD, PNF, retransplantation, or vascular complications. ${ }^{1,21}$ Conversely, a recent systematic review reported a significantly increased rate of EGD in the moderate steatosis group when compared with nonsteatotic groups. In addition, a trend toward a higher rate of PNF in these groups was described but it lacked statistical significance. ${ }^{22}$ Notably, this review demonstrated that there were large heterogeneities among the included studies in regard to the definition of PNF and EGD. Additionally, the studies that showed these significant results had few participants.

With regard to biliary complications, Frongillo et al reported an increased incidence of ischemia time biliary lesions in a mild/ moderate group of steatosis. ${ }^{23}$ In line with this report, an Italian multicentre study concluded that MaS $>25 \%$ was an independent risk factor for predicting posttransplant biliary complications. ${ }^{24}$ Both studies attributed these results to the compression of the hepatic sinusoidal space by fatty vacuoles, causing partial, or complete obstruction with a subsequent compromise of the hepatic microcirculation which led to a reduction in tolerance to Ischaemia/Reperfusion (I/R) injury and increased susceptibility to infections. Conversely, our analysis demonstrated no significant variations among patients who received steatotic livers in either category during the first 6 postoperative months which was similar to the results of previous studies. ${ }^{1,21}$ We supposed that differences in the rate of biliary complications were due to the variance between group numbers and this was one of the limiting factors in our study.
Interestingly, it was noticed that the ACR rates were inversely proportional to the degree of steatosis in both categories, being the lowest among the moderate groups (18.8 and 15.8\%, respectively) compared with the mild (32 and $32.5 \%$, respectively) and control groups (39.7 and 39\%, respectively). However, there was no statistical difference in either category $(p=0.161$ and 0.111 , respectively). Cho et al reported that $16.7 \%$ of patients who received nonsteatotic grafts had ACR after LT compared with $5.4 \%$ of the recipients of steatotic livers. ${ }^{25}$ Similarly, Hejlova et al demonstrated a higher rate of ACR among patients who received grafts with no steatosis (6.5\%) than among those who received steatotic grafts (4.4\%). ${ }^{26}$ In addition, Subramanian et al reported that non HCV recipients who received moderate/severe MaS grafts experienced a lower rate of ACR (16.7\%) than did the mild (30\%) and control (36\%) groups. ${ }^{27}$ The steatotic livers may have been preconditioned by multiple previous liver insults during the pathogenesis of steatosis. Therefore, these grafts could greatly tolerate the inflammation elicited by the disparity between the donor and recipient.

In addition, no cases in the moderate groups of MaS or MiS had HCV recurrence within the first 6 months post LT but there was not a significant difference when compared with the mild and control groups of each category $(p=0.423$ and 0.366 , respectively). Similarly, Botha et al documented that mild and moderate graft MaS has no impact on HCV recurrence after LT for HCV related cirrhosis. Donor age and CIT were the likely risk factors associated with the increase of HCV recurrence. ${ }^{28}$

In our study, the 1,3, and 5-year patient and graft survival rates were equal in the moderate groups and were 94,88 , and 
$81 \%$, respectively, in the MaS category and 89,83 , and $76 \%$, respectively, in the MiS category. In comparison with the mild and control groups in each category, no statistical significance was observed.

Some limitations are considered in light of these results. First, the present analysis was derived from a retrospective study. Second, there was a low number of moderate groups of steatosis in both categories which could lead to a $\beta$ error. Finally, in this study, we have demonstrated excellent post LT short and long-term outcomes using grafts with mild and moderate degrees of steatosis with nearly equal results with regard to the type of steatosis.

Additionally, possible advantages of the steatotic grafts have emerged in the form of decreasing the ACR rate postoperatively. Therefore, these grafts should be considered normal grafts and research should now be directed toward the use of severely steatotic livers. Moreover, the D-MELD score is a trustworthy tool for assigning donor-recipient risk factors that can be used safely in marginal graft allocation.

\section{Conclusion}

Excellent post LT long-term outcomes using grafts with mild and moderate steatosis were determined. Further studies are needed to evaluate the newly proposed relationship between ACR and steatosis.

\section{Source of Funding}

None.

\section{Conflicts of Interest}

None.

\section{References}

1 Angele MK, Rentsch M, Hartl WH, et al. Effect of graft steatosis on liver function and organ survival after liver transplantation. Am J Surg 2008;195(02):214-220

2 Nocito A, El-Badry AM, Clavien PA. When is steatosis too much for transplantation? J Hepatol 2006;45(04):494-499

3 Machado MV, Cortez-Pinto H. Non-invasive diagnosis of nonalcoholic fatty liver disease. A critical appraisal. J Hepatol 2013;58 (05):1007-1019

4 Todo S, Demetris AJ, Makowka L, et al. Primary nonfunction of hepatic allografts with preexisting fatty infiltration. Transplantation 1989;47(05):903-905

5 McCormack L, Petrowsky H, Jochum W, Mullhaupt B, Weber M, Clavien PA. Use of severely steatotic grafts in liver transplantation: a matched case-control study. Ann Surg 2007;246(06): 940-946, discussion 946-948

6 Noujaim HM, de Ville de Goyet J, Montero EF, et al. Expanding postmortem donor pool using steatotic liver grafts: a new look. Transplantation 2009;87(06):919-925

7 Wong TC, Fung JY, Chok KS, et al. Excellent outcomes of liver transplantation using severely steatotic grafts from brain-dead donors. Liver Transpl 2016;22(02):226-236

8 Tandoi F, Salizzoni M, Brunati A, Lupo F, Romagnoli R. Excellent outcomes of liver transplantation using severely steatotic grafts from brain-dead donors. Liver Transpl 2016;22(03):377-378
9 Fishbein TM, Fiel MI, Emre S, et al. Use of livers with microvesicular fat safely expands the donor pool. Transplantation 1997; 64(02):248-251

10 Yoong KF, Gunson BK, Neil DA, et al. Impact of donor liver microvesicular steatosis on the outcome of liver retransplantation. Transplant Proc 1999;31(1,2):550-551

11 Soejima Y, Shimada M, Suehiro T, et al. Use of steatotic graft in living-donor liver transplantation. Transplantation 2003;76(02): 344-348

12 Cieślak B, Lewandowski Z, Urban M, Ziarkiewicz-Wróblewska B, Krawczyk M. Microvesicular liver graft steatosis as a risk factor of initial poor function in relation to suboptimal donor parameters. Transplant Proc 2009;41(08):2985-2988

13 Agha RA, Borrelli MR, Farwana R, et al. Impact of the PROCESS guideline on the reporting of surgical case series: a before and after study. Int J Surg 2017;45:92-97

14 Dindo D, Demartines N, Clavien PA. Classification of surgical complications: a new proposal with evaluation in a cohort of 6336 patients and results of a survey. Ann Surg 2004;240(02):205-213

15 Clavien PA, Camargo CA Jr., Croxford R, Langer B, Levy GA, Greig PD. Definition and classification of negative outcomes in solid organ transplantation. Application in liver transplantation. Ann Surg 1994;220(02):109-120

16 OPTN policies.Available from: https://optn.transplant.hrsa.gov/ media/1200/optn_policies.pdf2016

17 Olthoff KM, Kulik L, Samstein B, et al. Validation of a current definition of early allograft dysfunction in liver transplant recipients and analysis of risk factors. Liver Transpl 2010;16(08):943-949

18 International Working Party. Terminology for hepatic allograft rejection. Hepatology 1995;22(02):648-654

19 Koch M, Garden OJ, Padbury R, et al. Bile leakage after hepatobiliary and pancreatic surgery: a definition and grading of severity by the International Study Group of Liver Surgery. Surgery 2011;149(05):680-688

20 Hisatsune H, Yazumi S, Egawa H, et al. Endoscopic management of biliary strictures after duct-to-duct biliary reconstruction in rightlobe living-donor liver transplantation. Transplantation 2003;76 (05):810-815

21 Westerkamp AC, de Boer MT, van den Berg AP, Gouw AS, Porte RJ. Similar outcome after transplantation of moderate macrovesicular steatotic and nonsteatotic livers when the cold ischemia time is kept very short. Transpl Int 2015;28(03):319-329

22 Chu MJ, Dare AJ, Phillips AR, Bartlett AS. Donor hepatic steatosis and outcome after liver transplantation: a systematic review. J Gastrointest Surg 2015;19(09):1713-1724

23 Frongillo F, Lirosi MC, Sganga G, et al. Graft steatosis as a risk factor of ischemic-type biliary lesions in liver transplantation. Transplant Proc 2014;46(07):2293-2294

24 Baccarani U, Isola M, Adani GL, et al. Steatosis of the hepatic graft as a risk factor for post-transplant biliary complications. Clin Transplant 2010;24(05):631-635

25 Cho JY, Suh KS, Lee HW, et al. Hepatic steatosis is associated with intrahepatic cholestasis and transient hyperbilirubinemia during regeneration after living donor liver transplantation. Transpl Int 2006;19(10):807-813

26 Hejlova I, Honsova E, Sticova E, et al. Prevalence and risk factors of steatosis after liver transplantation and patient outcomes. Liver Transpl 2016;22(05):644-655

27 Subramanian V, Seetharam AB, Vachharajani N, et al. Donor graft steatosis influences immunity to hepatitis $C$ virus and allograft outcome after liver transplantation. Transplantation 2011;92 (11):1259-1268

28 Botha JF, Thompson E, Gilroy R, et al. Mild donor liver steatosis has no impact on hepatitis $C$ virus fibrosis progression following liver transplantation. Liver Int 2007;27(06):758-763 